\title{
Pruebas de diagnóstico para detectar la COVID-19: una metodología híbrida
}

\author{
Diagnostic tests for COVID-19 detection: A hybrid methodology
}

\begin{abstract}
Alvaro Díaz-Badillo', María de Lourdes Muñoz², María Concepción Morales-Gómez³, José D. Martínez-Ezquerro ${ }^{4}$, Rosa María Quispe-Siccha ${ }^{5}$ y Juan C. López-Alvarenga ${ }^{1 *}$

${ }^{1}$ Departamento de Genética Humana, Universidad de Texas del Valle del Río Grande, Edinburg, Texas, Estados Unidos; ${ }^{2}$ Departamento de Genética y Biología Molecular, Centro de Investigación y de Estudios Avanzados, Instituto Politécnico Nacional, Ciudad de México, México; ${ }^{3}$ Departamento de Ingeniería en Biotecnología, Universidad Tecnológica de Tecámac, Tecámac, Estado de México, México; ${ }^{4}$ Unidad de Investigación Epidemiológica y en Servicios de Salud, Área de Envejecimiento, Centro Médico Nacional Siglo XXI, Ciudad de México, México; ${ }^{5}$ Unidad de Investigación y Desarrollo Tecnológico, Hospital General de México Dr. Eduardo Liceaga, Ciudad de México, México
\end{abstract}

El diagnóstico clínico es un requisito para iniciar un tratamiento adecuado en la práctica médica diaria. La implementación del tratamiento es variada: observar, prescribir medicamentos, iniciar procedimientos quirúrgicos, profilaxis para futuras complicaciones, prevención de combinación inadecuada de medicamentos $y$, en estos tiempos, aislamiento u hospitalización de pacientes con enfermedad por coronavirus 2019 (COVID-19).

El coronavirus tipo 2 del síndrome respiratorio agudo grave (SARS-CoV-2) es un tipo de coronavirus humano de origen zoonótico formado por ARN monocatenario, y es el agente causal de la pandemia actual de COVID-19. El espectro de la enfermedad es amplio: puede ser asintomática, producir síntomas leves o provocar enfermedad respiratoria aguda o neumonía grave. Actualmente no hay ningún tratamiento específico ni vacuna aprobados oficialmente.

Si se detecta la presencia del virus de la COVID-19 en personas asintomáticas se las podría aislar y con ello posiblemente evitar la expansión de la enfermedad hacia personas con alto riesgo de complicaciones, como pudieran ser los adultos mayores y aquellas con deficiencias inmunitarias. Es de notar que estos son los grupos más atacados por la influenza estacional, lo que contrasta con la pandemia de A H1N1 en 2009, que afectó en forma grave a personas menores de 65 años y sin complicaciones ${ }^{1}$.

Para definir la exactitud diagnóstica de las pruebas de detección se debe conocer la epidemiología de la enfermedad. Los reportes en la red de internet, como la página de seguimiento de COVID-19 del John Hopkins Coronavirus Resource Center ${ }^{2}$, indican que para el 16 de mayo de 2012 se habían registrado en México 45,032 casos confirmados, y de ellos, 4767 muertes. Hay que considerar que existe retraso en llevar los datos desde un hospital hasta la red electrónica. La tasa de casos-fatalidad la calcularon en un $10.6 \%$, cifra que contrasta con el $4.1 \%$ de California, el $6.7 \%$ de Boston o el $7.9 \%$ de Nueva York ${ }^{3}$.

Revisando el monitoreo nacional de COVID-19 del Instituto de Investigaciones Geológicas y Atmosféricas $^{4}$, la estimación del modelo centinela es de 394,257 casos, de los cuales se han confirmado 51,229 y han fallecido 5,703 personas (el día 17 de mayo de lo reportado por John Hopkins). Obtuvimos el dato de 163,691 personas que se han realizado alguna prueba en México ${ }^{3}$. También se cuenta con información de otros países, y en Estados concretos donde vive un alto porcentaje de mexicoamericanos, como Texas, se han realizado 678,471 pruebas, de las cuales 46,999 son casos positivos, y además se informa de

\footnotetext{
Correspondencia:

*Juan C. López-Alvarenga

Rio Grande Valley, 1201

Fecha de recepción: 22-05-2020

C.P. 78539 , Edinburg, Texas, USA

E-mail: juan.lopezalvarenga@utrgv.edu

Fecha de aceptación: 08-06-2020

DOI: $10.24875 / C I R U . M 20000068$

0009-7411/@ 2020 Academia Mexicana de Cirugía. Publicado por Permanyer. Este es un artículo open access bajo la licencia CC BY-NC-ND (http://creativecommons.org/licenses/by-nc-nd/4.0/).

Cir Cir. 2020;88(5):537-541 Contents available at PubMed www.cirugiaycirujanos.com
} 

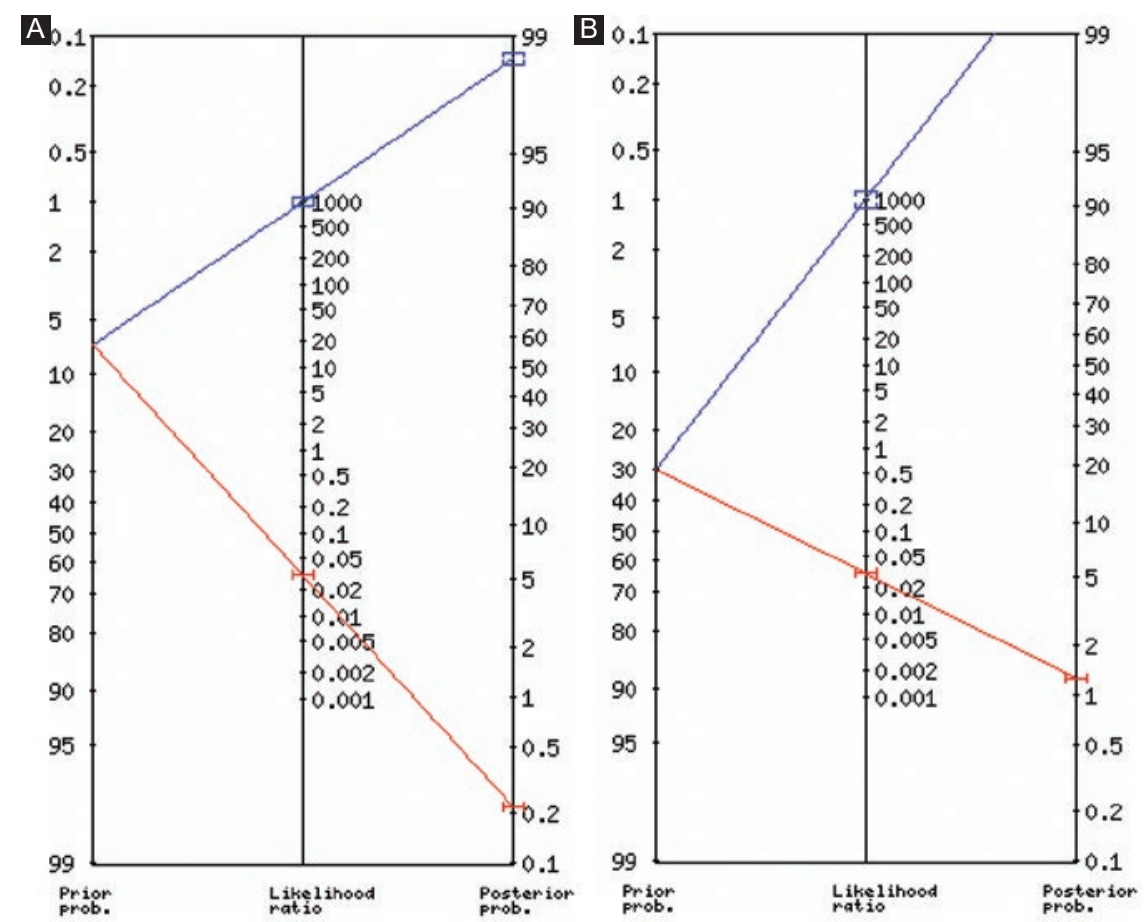

Figura 1. Nomograma de Fagan para calcular las probabilidades antes y después de la prueba. Datos de Texas. A: la probabilidad es de 0.069 antes de la prueba y se considera una sensibilidad de 0.97 y una especificidad de 0.999. B: la probabilidad preprueba en México de presentar COVID-19 es de 0.3, con las mismas sensibilidad y especificidad diagnósticas. La línea diagonal superior del nomograma es la $L R+y$ la inferior es la LR-. La probabilidad posprueba se muestra con su intervalo de confianza del IC95\%. (Diagnostic test calculator, versión 2010042101: http://araw.mede.uic.edu/cgi-bin/testcalc.pl).

fatalidad en 1,305 casos. La moda de edad de los enfermos se encuentra entre los 40 y 49 años, pero la mayor fatalidad ocurre en las personas mayores de 80 años, aunque afecta a todas las edades en menor proporción.

De manera aproximada, en Texas, el $6.9 \%$ de las personas a las que se ha realizado una prueba han resultado positivas, y se ha reportado que el $2.8 \%$ de las personas infectadas han fallecido. Todavía estos cálculos son muy imprecisos, pero pueden ser útiles a pesar de no saber cuáles fueron la sintomatología y las circunstancias en que se indicaron las pruebas diagnósticas.

¿Para qué sirven todos estos números? Ayudan a calcular la probabilidad preprueba. En Texas se hacen pruebas a pacientes sospechosos, pero también las hacen laboratorios privados que reportan la casuística al Estado. Entonces, la probabilidad de padecer COVID-19 antes de la prueba es de 0.069, y considerando que la reacción en cadena de la polimerasa en tiempo real (RT-PCR) tiene una sensibilidad del 97\% y una especificidad del $100 \%$ no significa que sea $100 \%$ el diagnóstico correcto. Se pueden calcular la razón de verosimilitud positiva $[\mathrm{LR}+=$ sensibilidad /
(1 - especificidad)] y la razón de verosimilitud negativa [LR- = (1 - sensibilidad) / especificidad]. Si consideramos en forma razonable que la especificidad es de 0.999 , en cada muestra de 100,000 individuos tendremos 6,900 enfermos, de los cuales 207 serán falsos negativos, y del resto, 93,100 personas sin infección, tendremos 93 falsos positivos (calculados con el nomograma de Fagan ${ }^{5}$, panel izquierdo de la figura 1). Estos falsos positivos pueden corresponder a problemas técnicos, contaminación o presencia de restos del virus en la mucosa. Se han reportado pruebas positivas en personas que tenían antecedente de ser casos positivos para COVID-19 y tuvieron una «reinfección". Sin embargo, hasta la fecha no se ha demostrado que estos individuos tuvieran capacidad para infectar ${ }^{6}$, y tampoco se ha podido obtener reinfección en modelos de primates no humanos ${ }^{7}$.

\section{Acotar quién debe hacerse una prueba para la COVID-19}

La anamnesis de síntomas como fiebre, tos o dificultad ligera para respirar, y el contacto cercano con una persona que se sabe que tiene COVID-19 o ha 
viajado recientemente desde un área contaminada, son indicación para permanecer en casa y consultar la atención médica. Los pacientes mayores y las personas que tienen afecciones médicas subyacentes graves o están inmunocomprometidos deben comunicarse con su proveedor de atención médica de forma inmediata, incluso si los síntomas son leves. Si alguna persona tiene síntomas graves, como dolor o presión persistentes en el pecho, confusión, disminución de la lucidez, incapacidad para despertar o labios azulados, inmediatamente hay que comunicarse y acudir a una clínica o sala de emergencias de algún hospital y buscar atención médica. El personal de salud capacitado determinará si debe hacerse una prueba diagnóstica de confirmación, y en tal caso tomará una muestra nasal con hisopo largo o también de saliva (esputo) para realizar un análisis de laboratorio.

Si las pruebas se hacen en pacientes con las características descritas, aumenta la probabilidad preprueba. Aceptemos que la probabilidad de tener COVID-19 si se indica la prueba en México es de 0.31 (4.5 veces mayor que lo calculado en Texas), y consideremos que solo se hace cuando es un caso con mucha sospecha; de esta forma, manteniendo la utilidad diagnóstica que calculamos en Texas, de cada 100,000 individuos con la prueba tendríamos 30,000 enfermos, y de ellos, 900 falsos negativos. En cuanto a los 70,000 negativos, podríamos tener solo 70 falsos positivos. La probabilidad de tener COVID-19 si la prueba fuera positiva es del 99.9\% (Fig. 1 B).

\section{Plataformas moleculares para diagnosticar específicamente la COVID-19}

La PCR es una técnica molecular que permite hacer copias de una determinada región de ADN in vitro. La PCR depende de una enzima (ADN polimerasa) termoestable, la Taq polimerasa, y requiere cebadores (o iniciadores) de ADN diseñados específicamente para la región de ADN de interés. Los resultados se obtienen en algunas horas y tiene suficiente especificidad para diferenciar el virus de la COVID-19 de otros virus con síntomas similares ${ }^{8}$.

La técnica de PCR brinda tres características útiles en situaciones de pandemia: es específica, puede diferenciar entre dos microorganismos muy cercanos evolutivamente; es sensible, detecta cantidades de hasta 15 copias e incluso menos del material genético viral; y finalmente es una técnica anticipada, es decir, se puede detectar el virus en las primeras fases de las complicaciones respiratorias. Sin embargo, surge la necesidad de considerar alternativas de diagnóstico más rápido ante la probabilidad de aparición de variantes genéticas en la evolución del virus.

\section{Plataformas serológicas para diagnóstico rápido de la COVID-19}

Considerando los «pormenores técnicos» que conlleva la técnica de PCR, actualmente se cuenta con pruebas de diagnóstico rápido en una gota de sangre de un dedo. Estas permiten conocer en menos de 10 minutos si una persona está o no infectada. Las pruebas rápidas serológicas miden el desarrollo de inmunoglobulinas (Ig) como las de clase IgM, que son los primeros anticuerpos que se forman ante la infección; su concentración no es muy alta y tienen corta duración, por lo que su detección indica infección aguda. Una excepción es que la IgM puede medir la actividad de una enfermedad en estadios crónicos (como en la hepatitis B).

Los anticuerpos específicos de clase IgG son los que más abundan en nuestro cuerpo, pero pueden tardar un tiempo en formarse después de una infección o vacunación. La concentración de IgG aumenta hasta alcanzar, entre 3 y 6 semanas después de la infección, una meseta que muy lentamente desciende. Su persistencia suele ser prolongada, mucho más allá de la curación del enfermo, y en ocasiones es detectable durante toda la vida.

La detección de IgM específica a unas concentraciones determinadas, dada la brevedad de su duración, nos faculta para realizar un «probable» diagnóstico de infección aguda. Por otra parte, la observación de un incremento en la concentración de lgG específica en dos muestras separadas en el tiempo (una en fase aguda y otra en fase convaleciente, habitualmente 2 semanas) indica la presencia de un estímulo antigénico en ese momento, o lo que es lo mismo, la existencia de una infección aguda 9 . Además, pueden ser de utilidad para analizar la persistencia de inmunidad.

\section{Plataformas nanoestructuradas para la identificación cualitativa a largo plazo del virus de la COVID-19}

En los últimos años, la espectroscopía Raman se ha utilizado para la identificación rápida de materiales desconocidos, como el análisis de productos químicos de alta pureza, la medición de ingredientes farmacéuticos o la caracterización de polímeros. La 

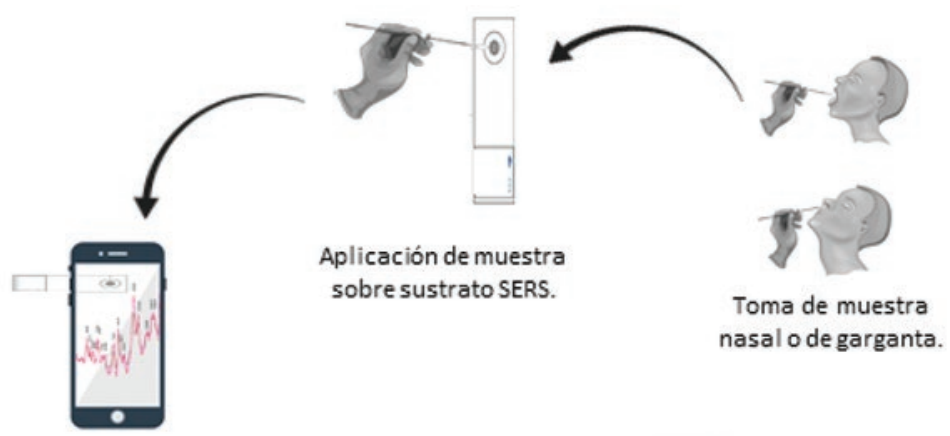

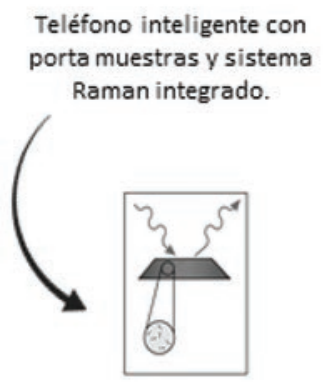

Lectura de muestra depositada en sustrato SERS y envío remoto de datos.
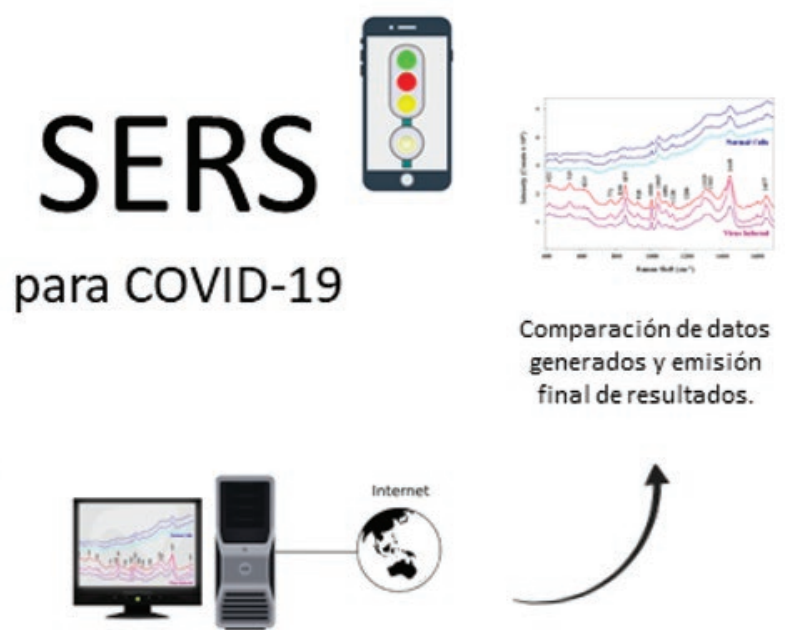

Bases de datos con

información

espectrométrica conocida.

Figura 2. Metodología de espectroscopía Raman para COVID-19.

instrumentación de plataformas nanoestructuradas emplea un software inteligente para la toma de decisiones y se auxilia de bibliotecas espectrales integradas, lo que la convierte en una técnica ideal para propósitos de análisis molecular.

Esta espectroscopía utiliza la dispersión de la luz procedente de un láser monocromático para explorar la estructura molecular de la materia. De cada millón de fotones dispersos, un solo fotón interactuará con los estados vibratorios de una molécula de la muestra analizada y emitirá luz de una longitud de onda diferente. Por su parte, la técnica SERS (espectroscopía Raman intensificada por efecto de superficie) (Fig. 2) aumenta la sensibilidad y la especificidad, por lo que resulta una técnica con aplicaciones analíticas en enfermedades infecciosas como la COVID-19.

Los avances en el campo de la miniaturización de componentes han conducido al diseño de dispositivos Raman manuales, portátiles y de alto rendimiento. EI procedimiento de análisis de las muestras implica la calibración del dispositivo para corregir inconsistencias asociadas a los errores de manipulación por parte de los operadores del aparato. Las metodologías creadas de este modo son confiables para la identificación inequívoca del material. El tiempo total de escaneo y el proceso de toma de decisión duran aproximadamente 20 segundos hasta obtener la «aprobación/desaprobación» del material o molécula en cuestión ${ }^{10}$.

El 8 de mayo de 2020, la Food and Drug Administration de los Estados Unidos autorizó la primera prueba de diagnóstico para COVID-19 que utiliza una muestra nasal para ser recolectada en casa. Consiste en un ensayo LTD (Laboratory Developed Test) de tipo molecular y alta especificidad, desarrollado por el Laboratorio Clínico de Genómica de Rutgers. La autorización de pruebas de diagnóstico adicionales con la opción de recolección de muestras en el hogar continuará aumentando el acceso de los pacientes a pruebas para la COVID-19. Esto proporciona una opción adicional para la recolección fácil, segura y conveniente de las muestras que se requieren para las pruebas, sin tener que ir a un consultorio médico, hospital o laboratorio. 


\section{Epílogo}

El abordaje de analizar la utilidad diagnóstica se hace desde una perspectiva bayesiana, en la que se conoce el resultado de la prueba y se analiza la probabilidad de presentar la enfermedad. Para ello se deben analizar lo más pronto posible los índices de exactitud diagnóstica interna, como sensibilidad y especificidad, que aplicados a la epidemiologia de la enfermedad desempeñan un papel importante para definir la población blanco a quien va dirigida la prueba diagnóstica, y la probabilidad de enfermedad y los falsos negativos luego de la prueba. Es claro que no es recomendable hacer un tamizaje indiscriminado en la población general abierta, ya que se malgastará el dinero público. La presencia de falsos negativos a medida que se hacen más pruebas irá en aumento. Conocer y aplicar estos índices ayudará a emplear los recursos públicos de forma eficiente.

\section{Financiamiento}

El presente artículo no contó con financiamiento.

\section{Conflicto de intereses}

Los autores declaran no conflicto de intereses.

\section{Bibliografía}

1. Centers for Disease Control and Prevention. 2009 H1N1 pnademic (H1N1pdm09 virus). (Consultado el 17 de mayo de 2020.) Disponible en: https://www.cdc.gov/flu/pandemic-resources/2009-h1n1-pandemic.html.

2. John Hopkins University \& Medicine. Coronavirus Resource Center. (Consultado el 16 de mayo de 2020.) Disponible en: https://coronavirus. jhu.edu/map.html.

3. Worldometer. Coronavirus. (Consultado el 17 de mayo de 2020.) Disponible en: https://www.worldometers.info/coronavirus/country/us/.

4. Instituto de Investigaciones Geológicas y Atmosféricas (IIGEA). COVID-19. Seguimiento. (Consultado el 17 de mayo de 2020.) Disponible en: http://iigea.com/amag/covid-19/.

5. Fagan TJ. Letter: nomogram for Bayes theorem. $\mathrm{N}$ Engl $\mathrm{J}$ Med. 1975;293:253.

6. Kirkcaldy R, King B, Brooks JT. COVID-19 and postinfection immunity: limited evidence, many remaining questions. JAMA. 2020 May 11. doi: 10.1001/jama.2020.7869. Online ahead of print.

7. Okhuese AV. Estimation of the probability of reinfection with COVID-19 by the susceptible-exposed-infectious-removed-undetectable-susceptible model. JMIR Public Health Surveill. 2020;6:e19097.

8. Corman VM, Landt O, Kaiser M, Molenkamp R, Meijer A, Chu DK, et al. Detection of 2019 novel coronavirus (2019-nCoV) by real-time RT-PCR. Euro Surveill. 2020;25:2000045.

9. Meyer B, Drosten C, Müller MA. Serological assays for emerging coronaviruses: challenges and pitfalls. Virus Res. 2014;194:175-83.

10. Fan C, Hu Z, Riley LK, Purdy GA, Mustapha A, Lin M. Detecting foodand waterborne viruses by surface-enhanced Raman spectroscopy. J Food Sci. 2010;75:M302-7. 